EMERGING VOICES

\title{
Meta-discourse Use of Egyptian Researchers Writing English Research Articles for International Publication
}

\author{
Ahmed Mohamed Alaa Eldin Mohamed*
}

\section{Introduction}

\subsection{Statement and Rationale of the Research Problem}

To publish a research article (RA), internationally or locally, the researcher should provide a well-written argument that is convincing to the readers. The researcher should be able to communicate his/her ideas in a way that serves the purpose of the research. Egypt's status of research international publication is found to require great improvement. Egypt ranks 36 out of 231 countries in research productivity, having a share of only $0.6 \%$ and $11 \%$ of international and regional research publications, respectively (Scopus, 2016). Moreover, the citation impact of the research articles published by Egyptian researchers is below average, denoting a score of 0.9 (Academy of Scientific Research and Technology, 2016).

Academic writing is high-stakes writing on which the careers of researchers depend. Several RAs written by non-native speakers of English can have excellent academic content which is an added value to the international body of research and a huge benefit to society, but they might not come to light because of the difficulties in presenting and explaining the ideas in the English language. Therefore, providing guidelines for Egyptian researchers to have well-written research is of high necessity to have more research by Egyptians published internationally.

* Ph.D. Candidate in the Department of English Language and Literature, Faculty of Arts, Cairo University. This paper is derived from an unpublished Ph.D. thesis entitled "Linguistic Challenges Facing Egyptian Researchers in Writing English Research Articles for International Publication" (Cairo University 2020), supervised by Prof. Norice W. Methias. The author also works as a freelance writer, translator, researcher, editor, proofreader, and English language instructor.

Cairo Studies in English 2020(1): https://cse.journals.ekb.eg/ 


\subsection{Significance and Aims of the Study}

In order to identify the challenges facing Egyptian researchers in writing their Scientific, Technical, and Medical (STM) research in English, there is a need to conduct a discourse analysis of RAs submitted for publication in international journals. However, this need is not sufficiently met by previous research. Hence, this study attempts to fulfill this need by analyzing how Egyptian researchers write their RAs in English in STM fields to be published internationally. Furthermore, this analysis is conducted on the unedited first drafts of the RAs prior to publication, which is, to the best of the researcher's knowledge, an approach that has never been adopted by previous research on the topic, which analyzed RAs after they have become published.

\subsection{Scope of the Study}

The current study is limited to analyzing the meta-discourse markers' usage (according to Hyland's 2005 framework) in STM RAs written by Egyptian researchers and submitted to international journals. The analysis is concerned with the body of the RAs, that is, the main sections of the RA (e.g., Introduction, Methods, Results, Discussion, and Conclusion). Any other parts of the RA are excluded from the analysis. Hyland's model of analysis has been chosen because it is well supported by a body of previous research. It belongs to the recent trends in analyzing discourse.

\section{Background of the Study and Literature Review}

\subsection{Genre Analysis and Academic Discourse}

It has long been established that there is a variety of forms of discourse and that each form, or genre, has its defining features. This theory of classifying discourse into genres has been the result of numerous works, starting from the theories and insights of ancient Greek philosophers and scientists to the research works of modern-day linguists. Genre theory investigates the nature of the differences between the diverse forms of discourse as well as the reasons behind these differences. It allows for predicting the language used and deducing the context in which it is used to recognize the generic identity of the discourse (Eggins and Martin, 1997). Genre theory has aimed at applying genre analysis to serve pedagogical purposes for the English for Specific Purposes (ESP) classroom, especially the academic and professional discourse classroom. Discourse and genre analysis have been popular and useful tools to acquire more understanding of social practices (Bhatia, 2012). It is of importance thus to shed more light on the definition and characteristics of the genre as well as to define 
genre analysis and pinpoint the significance of its application to the academic discourse and the ESP classroom.

2.1.1. Genre. According to Merriam-Webster online dictionary, the term genre means "a category of artistic, musical, or literary composition characterized by a particular style, form, or content". The word genre comes from French, based on a Latin origin, meaning type or kind. However, the term genre has a wider scope in linguistics.

According to Bakhtin (1986), genres are "relatively stable types" (p. 60) of communicative utterances that define the uniqueness of the language used in different contexts. Bakhtin (1986) further points out that changes in genres cannot be separated from the historical development of language. He describes genres as "the drive belts from the history of society to the history of language" (p. 65). Any development in language results in the rise of new genres as well as the restructuring of the already existing ones. Moreover, Bakhtin opines that the choice of a particular genre reflects the author's communicative will or plan. This choice is based on the specific nature of communication, the thematic or semantic content, the context, and the participants as well as the relationship between the addresser and the addressee. For example, the language used in popularized science articles is simple and general, which is different from that used in specialized RAs, each matching its author's objectives.

Bazerman (1988) defines genre as "a sociopsychological category which we use to recognize and construct typified actions within typified situations. It is a way of creating order in the ever-fluid symbolic world" (p. 319). Genre to Bazerman is more than a textual structure that distinguishes between the different texts and different contexts. It is a way to organize and even control language use in the community. Swales (1990), moreover, states that genres occur within the domain of discourse communities. A discourse community according to Swales is defined according to six characteristics: a) The discourse community members have commonly agreed-upon goals. b) The discourse community members have a clear form of communication among each other. c) They constantly communicate to provide information and feedback. d) A discourse community makes use of one or more genres to achieve its goals. e) A discourse community possesses specific vocabulary to be used within its genre(s). f) The discourse community members have a specific level of expertise in the content and the discourse as per the discourse community's needs. The communicative purpose is, therefore, at the heart of the whole process of driving the discourse community's language activities. 
Trosborg (1997) points out that genre is simply "a system for accomplishing social purposes by verbal means" (p. 6). Trosborg confirms the strong relationship between genre and its communicative social purpose. Paltridge (1997) also tackles the idea that genre is a solution to any frequent communicative problems in society. He argues that genres turn in time into conventionalized social events. A genre gradually becomes a standard model to be followed by the members of a society. However, he adds that genres are not static; they undergo constant change according to the communicative needs of the society. Thus, a genre, the same as language, evolves and develops according to the requirements of its environment.

Fairclough (2004) defines genre as "a way of acting and interacting linguistically" (p. 17). Genre is again seen as a way of communication through speech/text. Fairclough further opines that there are differences among the different genres as regards their degree of stabilization. Some genres, such as RAs, are highly fixed, while others, such as artworks and ads, are continually subject to change which makes them highly variable. Fairclough mentions that there is a non-stop pressure between the tendency to have more stabilized genres and the tendency to change according to the continuous change in society. What is more, Hyland (2011) defines genres as "the recurrent uses of more-or-less conventionalized forms through which individuals develop relationships, establish communities, and get things done using language" (p. 6). Hyland asserts the conventionalized nature of genres and their function to help individuals in a society communicate. Hyland adds, however, that genres act as an implicit agreement between the writers and the readers. Genres help the readers know what to expect from the writers and help the writers know how to approach their readers.

Bhatia (2013) defines genre as follows:

Genre is a recognizable communicative event characterized by a set of communicative purpose(s) identified and mutually understood by members of the professional or academic community in which it regularly occurs... It most often is a highly structured and conventionalized communicative event... Various genres display constraints on allowable contributions in terms of their intent, positioning, form and functional value... These constraints are often exploited by the expert members of the discourse community to achieve private intentions within the framework of socially recognized purpose(s) (Bhatia 2013, 49-52). 
Bhatia's definition confirms that genres are conventionalized and highly standardized forms of language aiming at specific communicative goals. Genres also may constrain language use, yet expert community members can use these constraints to create new patterns to serve their communicative purpose. Bhatia also points out that genres may have interdisciplinary variations. For instance, a law textbook may cut across the disciplines of law and science.

2.1.2. Genre Analysis. Genres show how the members of a certain society understand, build, and use the language in a mostly similar way (Bhatia 2014). The analysis of genres therefore leads to having a clearer and more insightful image of language and societies. Genre analysis is "the study of situated linguistic behavior in institutionalized academic or professional settings" (Bhatia 2014, p. 26). It is based on discourse analysis. Bhatia (2014) also defines it as "the study of naturally occurring written discourse focusing in particular on its analysis beyond the sentence level" (p. 3). Genre analysis has been offered as a deeper and thicker type of discourse analysis, marking the shift from description to explanation and from the surface level towards the deep level of language use.

The shift from discourse analysis to genre analysis addresses two points of inadequacy. Genre analysis determines and explains the boundaries and expectations of the various genres. In addition, genre analysis focuses more on the communicative aspects of the different types of discourse, providing space for the interpretation of the different texts. It also sheds light on the functional aspect as well as the applied aspect of language (Bhatia, 2013). Genre analysis, hence, explains how language varies in the specific types of discourse used in specific cultures. In the academic context, for example, genre analysis can highlight the differences in the language used in textbooks, RAs, theses, presentations, and so on. Further, it explains the strategies needed to appropriately address and formulate these types of discourse.

Genre analysis is based on 3 types of orientation. The first is the linguistic one, mainly realized through discourse analysis, which deals with the analysis of the language and rhetorical structure of texts. The second type of orientation is the sociological one. This helps better understand how a genre works to identify, construct, and achieve the communicative goals of a certain discourse community. Unlike the linguistic type of orientation which gives the priority to the text, the sociolinguistic type of orientation asserts the fact that a text cannot work in isolation and that its meaning goes hand in hand with a social process of constant interaction and negotiation. The third type of orientation is psycholinguistic. It is the tactical aspect of language use. It reveals the cognitive and linguistic strategies of the writer to formulate his/her ideas and aims in the 
genre (Bhatia, 2013). Therefore, genre analysis is a three-dimensional analysis which comprises discourse analysis, sociolinguistics, and psycholinguistics.

2.1.3. Academic Discourse. The RA is realized under the framework of academic discourse. Academic discourse is "the ways of thinking and using language which exist in the academy...Textbooks, essays, conference presentations, dissertations, lectures, and RAs are central to the academic enterprise and are the very stuff of education and knowledge creation" (Hyland, 2011, p.1). Hyland concludes his definition by pointing out that "discourse is at the heart of the academic enterprise" (1). It is through discourse that the academic contributions come to being.

Hyland (2011) discusses the features of academic discourse. Firstly, academic texts are seen as seeking persuasion and agreement with the readers. Writers use a language which is easily recognized and expected by the reader. Academic texts follow a group of agreed-upon systemic formal rules and this helps the writer to appear more persuasive. Secondly, this persuasion in academic discourse is realized through interpersonal interactions and negotiations through the text. Writers use a variety of linguistic techniques to establish rapport with the readers, to back up and validate their views, and to mention and discuss the views of others. This dialogue with the readers makes the writer's argument more convincing and acceptable. Thirdly, academic texts have specific rhetorical structures according to each discipline. The writer should be aware of the conventional rhetorical structure of his/her discipline so that his/her work is approved by the academic community of this discipline. Fourthly, the language of the academy has some special features. Academic texts use citations heavily, especially to the more recent and original references, to ensure that the content is built upon the works of others and that it is supported with valid and up to date evidence. The language of academic texts shows a considerable amount of mitigation and hedging as well, where the writer avoids total commitment to the idea stated in his/her arguments. Adding to this, coordinating conjunctions are highly adopted to explicitly link ideas. Finally, academic discourse is less tolerant to divergence from the shared rules of writing and especially to plagiarism, where the content has to be authentic and original.

2.1.4. Meta-discourse. According to Hyland (2005), meta-discourse as a term was first introduced in the late 1950s as a means to understand language use. It aimed to correct the previous views which considered language as merely descriptive and propositional. From then on, meta-discourse has witnessed many developments. It deals with the communication in language not only on the level 
of conveying information but also on the level of the personality and attitudes of the writers and readers through investigating how their interaction is expressed in the text. As Hyland (2005) phrases it, meta-discourse provides "a framework for understanding communication as social engagement" (p. 4). It shows the means with which the writers present their attitudes towards their text as well as their readers.

Hyland (2005) defines meta-discourse as follows: "Meta-discourse is the cover term for the self-reflective expressions used to negotiate interactional meanings in a text, assisting the writer (or speaker) to express a viewpoint and engage with readers as members of a particular community" (p. 37). Simply put, meta-discourse is "discourse about discourse" (Hyland 2005, p. 16). It is a way to show how writers organize and present their ideas and interact with the readers. It emphasizes the means of communication and expressing thoughts and attitudes through the text. It also relates the context to the text through emphasizing the interactive and interactional role of discourse where the writer shows an understanding of the readers' needs and addresses them in a clear context. Moreover, meta-discourse is based on three key principles. The first principle is that meta-discourse is different from proposition in that it is a fundamental part of the text and its meaning, since, unlike proposition; it links the text to a certain context and social group. The second principle is that metadiscourse expresses the interactions between the writer and the readers for communicating effectively. It is a realization of the interconnection between textual and interpersonal markers of discourse. The third principle is that metadiscourse differentiates between internal and external aspects of discourse and that it is concerned with the internal ones. It serves to internally construct and organize the argument in discourse instead of merely reporting external world events (Hyland, 2005).

Meta-discourse is founded on writing as a social and communicative event. It has brought the interpersonal aspect of discourse to the surface. It is essential to effectively communicate the writer's ideas and responses to the readers' concerns, and this comes true through meta-discourse. This is particularly evident in academic discourse. It helps provide "a more comprehensive way of examining interaction in academic argument" (Hyland 2011, p. 16). Writing academic works is not only concerned with presenting a certain theory or reality. It is also concerned with negotiating these ideas and convincing the readers about their correctness. Meta-discourse is used as a resource to help academic writers shape their arguments and provide a persuasive content through controlling the degree of personality in the text. Meta-discourse also helps the writer show the degree of social engagement, writer commitment and attitude, and reader 
involvement in the text. The study of meta-discourse is of importance, thus, to help writers, both native and non-native, to present their ideas and to communicate with the readers successfully. It can also help teachers guide students into exploring academic writing and producing a more effective academic writing practice (Hyland 2005; 2010).

\subsection{Previous Studies}

A number of studies analyzed the meta-discourse of academic RAs. For instance, Mozayan, Allami, and Fazilatfar (2018) studied the meta-discourse features in medical RAs. They analyzed the meta-discourse markers' usage of 160 RAs divided into 2 groups: 80 in Persian and 80 in English. The comparison of both groups showed that there were many differences in the frequency of usage of almost all the meta-discourse markers. They suggested that these differences are due to cultural, paradigmatic, and disciplinary influences. However, a similar comparison between RAs written by Egyptian authors and those written by native speakers of English can show equally important yet mostly different findings. Mina and Biria (2017) analyzed the meta-discourse markers in the Discussion section of 100 RAs in social and medical science written by Iranian researchers. They found that interactive discourse markers are employed more frequently in social science than in medical science RAs which has a higher rate of interactional meta-discourse markers. However, the study analyzed only one section of the RA and other sections may bring different findings. Liu and Huang (2017) analyzed the interactional meta-discourse markers in 289 abstracts written in English in the field of economics. They found a difference in the meta-discourse markers' usage between the Chinese and the English researchers. They suggested that this is mainly due to cultural and economic influences. The analysis dealt with one aspect of Hyland's metadiscourse framework as well as with abstracts in a Chinese economics journal only. Guziurová (2017) investigated the role of meta-discourse in genre analysis through the analysis of engagement markers in 7 textbooks for undergraduates and 8 RAs written by native speakers of English in linguistics. The comparison of these two academic genres showed that the inclusive 'we' was the engagement marker used with the highest frequency, fulfilling a variety of functions. The analysis of other types of meta-discourse markers would have provided more solid and comprehensive results, however.

Sorahi and Shabani (2016) compared the meta-discourse markers used in Persian to those used in English. They selected a sample of 40 Introduction sections of linguistics RAs, 20 Persian, and 20 English. They observed that the similarities in the meta-discourse markers' usage are much more than the 
differences. Their findings were, nevertheless, rather descriptive and were based on data extracted from only one section of the RA. Alotaibi (2016) compared the meta-discourse markers' usage in English and Arabic Introduction and Conclusion sections. He selected 20 Introduction sections and 20 Conclusion sections written in English by Arab researchers and compared them to the same number of sections but written in Arabic. The sample was in the field of humanities. He found that the English texts had more meta-discourse markers than the Arabic ones. He also found that the researchers relied more on metadiscourse markers in the Introduction sections than in the Conclusion sections. However, the analysis of the meta-discourse markers in all the different sections of the RA can depict different results. Mu, Zhang, Ehrich, and Hong (2015) analyzed the meta-discourse markers of 40 RAs in Applied Linguistics: 20 in English and 20 in Chinese. They found that the meta-discourse markers were used more frequently in the English RAs than in the Chinese ones. It was also observed that both groups used more interactive markers than interactional markers, but the English RAs used more interactional markers than the Chinese ones. The analysis of different scientific disciplines and the comparison of different language groups may show different results however.

Concerning studies which analyzed the meta-discourse of the RAs written by Egyptian researchers, to the best of the researcher's knowledge, only one study exists in the literature. Hosni (2015) analyzed the meta-discourse markers in the Discussion section of 90 linguistics RAs. She aimed to compare the Egyptian researchers' studies published in English and those published in Arabic. She found that the meta-discourse markers were used by the Egyptian researchers in the internationally published RAs more than the nationally published ones. She also found that they were used more in articles published in English than those published in Arabic. Nevertheless, Hosni's study focuses only on one section of the RA and on one field of study which is linguistics.

No studies have been conducted that analyze the meta-discourse usage in the whole sections of the RAs written by Egyptian researchers in the STM fields targeting publishing in international peer-reviewed journals. No studies have also analyzed the unedited first drafts of the RAs. This study, thus, attempts to address these gaps.

\subsection{Research Questions}

The current study seeks to answer the following questions:

1. How do the Egyptian researchers use the different meta-discourse markers in the unedited first drafts of their STM research articles in terms of Hyland's (2005) meta-discourse framework? 
a. What are the different interactive and interactional meta-discourse markers used in the selected sample?

b. What is the frequency of the different interactive and interactional meta-discourse markers used in the selected sample?

\section{Methodology}

\subsection{Research Design}

This study is a mixed-methods exploratory study. The design provides a qualitative framework, which is enriched with a quantitative framework of descriptive statistics. The design is also exploratory due to the scarcity of previous research on the matter of interest in the current study.

\subsection{Sample}

The unedited first drafts of 20 RAs were selected in a purposeful manner according to a number of inclusion criteria: a) a recent RA in the STM disciplines (not earlier than 2016); b) written by Egyptian researchers affiliated to Egyptian institutions; c) one researcher cannot be the author of more than one RA in the sample; d) submitted for publishing in an international journal. These criteria help make the sample within the scope of the study. They also help achieve transferable and representative results. The sample was selected from a pool of possible candidates, in order to cover for any possible sample attrition.

\subsection{Framework of Analysis}

Hyland's meta-discourse framework (2005) is used to analyze communication and social engagement through language use. It is an important tool that has been adopted by a plethora of previous studies (e.g., Alotaibi 2016; Sorahi and Shabani 2016; Liu and Huang 2017; Mina and Biria 2017).

Hyland divides meta-discourse into 2 main categories: interactive and interactional. Table 1, taken from Hyland (2010), defines the markers in each category. 
Table 1: Interactive and interactional meta-discourse markers (from Hyland 2010, 128-129).

\begin{tabular}{|c|c|c|}
\hline CATEGORY & FUNCTION & EXIMPLES \\
\hline Interactive & Help to guide reader through text & Resources \\
\hline Transitions & $\begin{array}{l}\text { express semantic relation between main } \\
\text { clauses }\end{array}$ & $\begin{array}{l}\text { in addition / but / thus / } \\
\text { and }\end{array}$ \\
\hline Frame markers & $\begin{array}{l}\text { refer to discourse acts, sequences, or } \\
\text { text stages }\end{array}$ & $\begin{array}{l}\text { finally / to conelude / } \\
\text { my purpose is }\end{array}$ \\
\hline $\begin{array}{l}\text { Endophoric } \\
\text { markers }\end{array}$ & $\begin{array}{l}\text { refer to information in other parts of the } \\
\text { text }\end{array}$ & $\begin{array}{l}\text { noted above / see Fig / } \\
\text { in secrion } 2\end{array}$ \\
\hline Evidentials & $\begin{array}{l}\text { refer to source of information from } \\
\text { other texts }\end{array}$ & $\begin{array}{l}\text { according to } X / C, \\
1090) / Z \text { states }\end{array}$ \\
\hline Code glosses & $\begin{array}{l}\text { help readers grasp meanings of } \\
\text { ideational material }\end{array}$ & $\begin{array}{l}\text { namely /e.g. / such as / } \\
\text { in other wonds }\end{array}$ \\
\hline Interactional & Involve the reader in the argument & Resources \\
\hline Hedges & $\begin{array}{l}\text { withhold writer's full commitment to } \\
\text { proposition }\end{array}$ & $\begin{array}{l}\text { might / perhaps / } \\
\text { possible / about }\end{array}$ \\
\hline Boosters & $\begin{array}{l}\text { emphasise force or writer's certainty in } \\
\text { proposition }\end{array}$ & $\begin{array}{l}\text { in fact / definitely / it is } \\
\text { clear that }\end{array}$ \\
\hline $\begin{array}{l}\text { Attitude } \\
\text { markers }\end{array}$ & express writer's attitude to pro-position & $\begin{array}{l}\text { unfortumately / I agree / } \\
\text { sunprisingly }\end{array}$ \\
\hline $\begin{array}{l}\text { Engagement } \\
\text { markers }\end{array}$ & $\begin{array}{l}\text { explicitly refer to or build relationship } \\
\text { with reader }\end{array}$ & $\begin{array}{l}\text { consider / note that / } \\
\text { you can see that }\end{array}$ \\
\hline Self mentions & explicit reference to author(s) & I/we/my/our \\
\hline
\end{tabular}

Interactive markers focus on the writers' need to establish, manage, and organize their ideas in order to meet the readers' expectations. They consist of transitions, frame markers, endophoric markers, evidentials, and code glosses. Transitions are conjunctions which mark mainly addition (e.g., and, moreover, etc.), comparison (e.g., likewise, similarly, etc.), contrast (e.g., but, however, etc.), and consequential steps (e.g., therefore, hence, etc.) between main clauses in the text. The use of these connectives and conjunctions is familiar in academic writing since they help guide the readers through the different phases of the writer's argument. Frame markers highlight the boundaries in the arguments in the text through labeling sequencing, argument goals, topic shifts, and text stages (e.g., first, then, in conclusion, in this section, in regard to, etc.). Endophoric markers refer to the information mentioned in other parts of the text (e.g., see Table, as previously stated, in the next section, etc.). Evidentials are the markers which reflect the sources outside the text from which the information inside the text is taken (e.g., X et al. (1999), [7], etc.). They are central for academic writing since writers are required to cite the source of information they use as evidence to support their argument and to make it more persuasive. Finally, code glosses provide clarification or exemplification of the information in the text (e.g., for example, i.e., in other words, etc.) (Hyland 2005; 2010). 
In contrast, interactional markers focus on getting the readers engaged and involved with the text. They include hedges, boosters, attitude markers, engagement markers, and self-mentions. Hedges are markers which reduce the writer's degree of commitment to the information provided and differentiate between facts and opinions, which is common practice in academic RAs (e.g., maybe, perhaps, possibly, etc.). Boosters are the direct opposite since they enhance and emphasize the writer's certainty in the information provided (e.g., obviously, it is clear, etc.). Attitude markers convey the writer's thoughts and beliefs about the information provided (e.g., prefer, unfortunately, remarkable, etc.). Engagement markers show direct communication with the readers where the writer explicitly refers to them (e.g., you, inclusive we, your, see, note, etc.). Lastly, self-mentions are the opposite of engagement markers where the writer directly refers to himself/herself (e.g., I, exclusive we, our, ours, etc.). In a nutshell, the different meta-discourse markers serve as linguistic devices which show the relationship between the writers and the readers (Hyland 2005; 2010).

\subsection{Data Collection and Analysis Procedures}

The unedited first drafts of 20 RAs were selected using a major publisher's database as per the set selection criteria. The selected sample was then prepared for analysis by excluding the parts not related to the scope of the analysis. After that, data analysis took place by using Hyland's (2005) meta-discourse framework for analyzing the use of the different textual markers. The frequency and variability of the meta-discourse markers used in each RA were calculated. After finishing the data analysis, peer checking of a sample from the data was employed to ensure the reliability of the analysis and help prevent any errors in the data interpretation. Finally, the outcomes of the data analysis were explained and discussed qualitatively and quantitatively.

\section{Results}

The meta-discourse analysis reveals interesting results. Meta-discourse allows highlighting communication through discourse under the framework of interactive and interactional markers. These markers portray how the writer communicates ideas and how he/she satisfies his/her needs and the readers' needs through language usage. On the whole, the results of the meta-discourse markers' analysis are shown in Table 2. 
Table 2: The results of the meta-discourse analysis.

\begin{tabular}{|c|c|c|}
\hline Marker & Frequency Count & Examples \\
\hline Interactive & 639 & and, but, therefore \\
\hline Transitions & 612 & $\begin{array}{c}\text { [11], Yamamoto et al. } \\
\text { (2015) }\end{array}$ \\
\hline Evidentials & 400 & namely, defined as, i.e. \\
\hline Code glosses & 189 & in Table 1, (Figure 2) \\
\hline Endophoric markers & 138 & in the present study, lastly \\
\hline Frame markers & \multicolumn{2}{|c|}{1978} \\
\hline Total & 264 & about, may, probably \\
\hline Interactional & 231 & exclusive 'we, our, us' \\
\hline Hedges & 47 & important, unfortunately \\
\hline Self-mentions & 28 & it was clear that, \\
definitely
\end{tabular}

It is found that the use of interactive markers far exceeds the use of interactional ones. From a total of 2551 meta-discourse markers in the data, 1978 markers are interactive $(77.5 \%)$ while only 573 are interactional $(22.5 \%)$. The mostly used meta-discourse marker in the analyzed data is the transitions, with 639 occurrences (i.e., $25 \%$ of the total meta-discourse markers). This is followed by the evidentials, with 612 occurrences (i.e., $24 \%$ of the total). It is worth noting that the occurrence of each of these two interactive markers surpasses the occurrence of all interactional markers combined. On the other hand, the marker of the least occurrences in the analyzed data is the engagement markers, with only 3 occurrences (i.e., $0.001 \%$ of the total). Boosters and attitude markers are from the least occurring markers as well with 28 (i.e., $0.01 \%$ of the total) and 47 (i.e., $0.02 \%$ of the total) occurrences, respectively. It is also worth reporting that in relation to the total number of words in each RA analyzed, RA 6 has the highest density of meta-discourse markers (131 markers in 1982 words, i.e., $6.1 \%$ ), while RA 3 has the lowest density of meta-discourse markers (57 markers in 1934 words, i.e., 3\%). The results of each type of meta-discourse markers are reported as follows.

\subsection{Interactive Markers}

Interactive meta-discourse markers help organize the text and guide the readers through their different ideas and stages. In the 20 analyzed RAs, there are 1978 interactive markers, spread across the RAs as shown in Figure 1. 


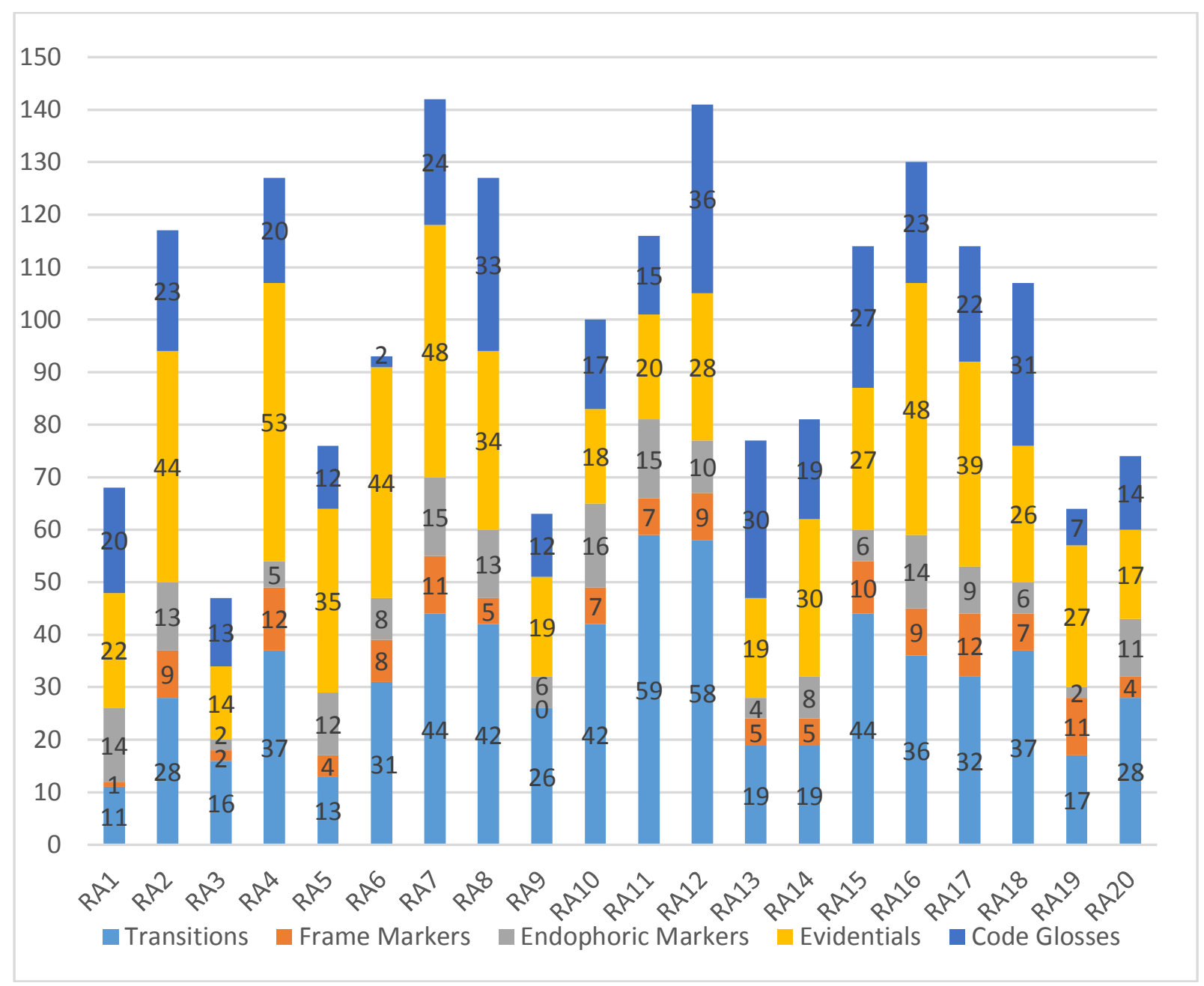

Figure 1: The results of the interactive meta-discourse markers' analysis.

As shown in Figure 1, RA 7 has the highest number of interactive markers (i.e., 142 interactive markers), while RA 3 has the lowest number with only 47 interactive markers. However, in relation to the total number of words in each RA, it is found that RA 15 has the highest density of interactive markers (114 interactive markers in 2229 words, i.e., $5 \%$ of the total number of words). In contrast, the RA with the lowest density of interactive markers remains RA 3 (47 interactive markers in 1934 words, i.e., 2.4\%).

Tackling the occurrences of each interactive marker separately, transitionsthe highest occurring interactive markers (i.e., 639 occurrences)-happen the most in RA 11, with 59 occurrences, while they happen the least in RA 1, with 11 occurrences. In regard to evidentials - the second most occurring marker in the data (i.e., 612 occurrences), they appear the most in RA 4, with 53 occurrences, while they appear the least in RA 3, with 14 occurrences. Code glosses are found the most in RA 12 (i.e., 36 occurrences) and the least in RA 6 
(i.e., 2 occurrences). Moving on to the endophoric markers, the highest number of their occurrences is in RA 10 (i.e., 16 occurrences), while the lowest number of their occurrences is in RAs 3 and 19 (i.e., 2 occurrences in each). Lastly, frame markers are used the most in RAs 4 and 17 (i.e., 12 occurrences in each), while they are used the least in RAs 1 and 9 (i.e., 1 and 0 occurrences, resp.).

\subsection{Interactional Markers}

Interactional meta-discourse markers help show the writer's voice as well as addressing the readers. There are a total of 573 interactional markers in the 20 analyzed RAs. These markers occur in each RA as shown in Figure 2.

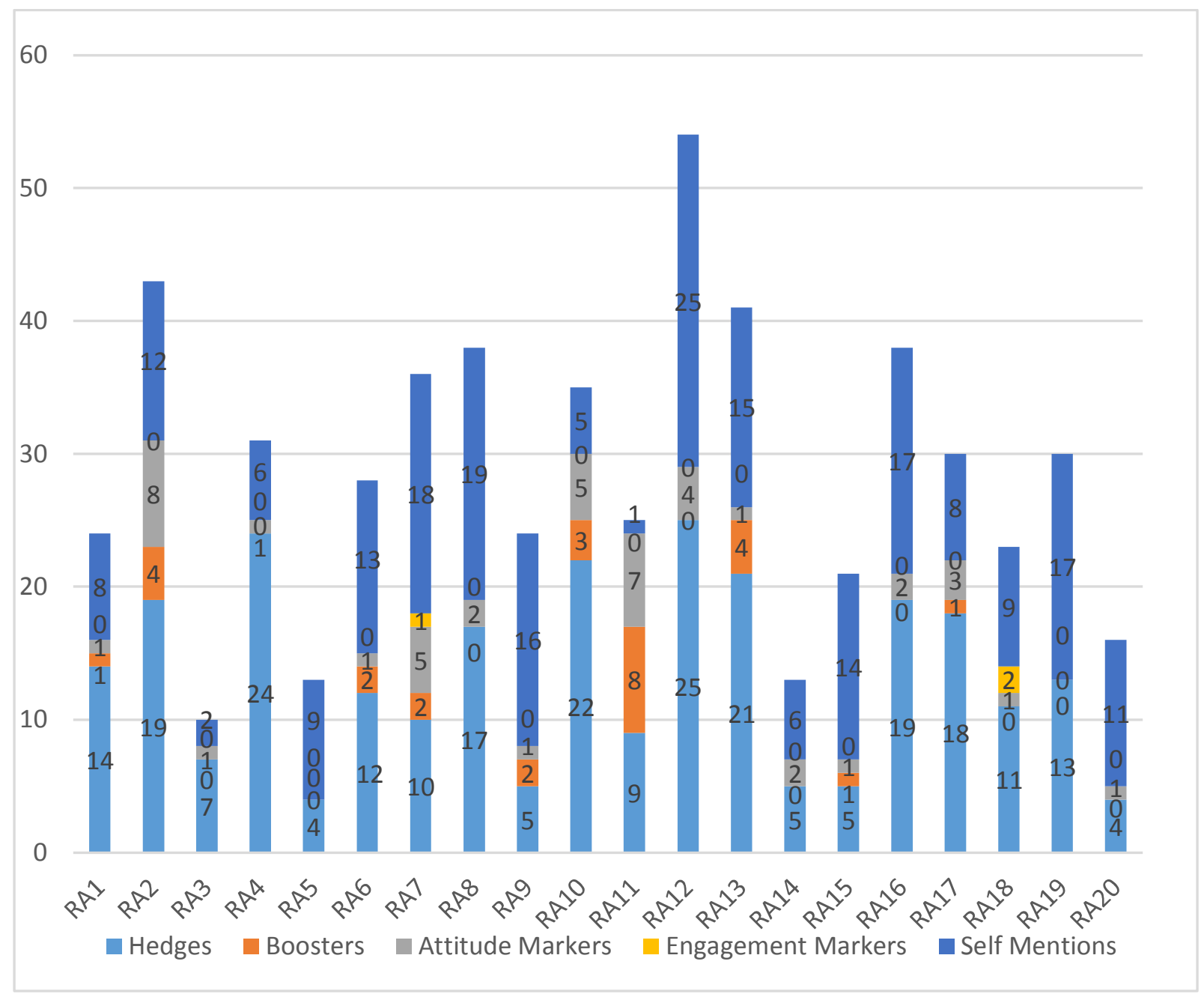

Figure 2: The results of the interactional meta-discourse markers' analysis

As shown in Figure 2, RA 12 has the highest number of interactional markers (i.e., 54 interactional markers) while RA 3 has the lowest number with only 10 interactional markers. However, in relation to the total number of words in each 
RA, RA 19 has the highest density of interactional markers (30 interactional markers in 1693 words, i.e., $1.7 \%$ of the total number of words). Conversely, the RA with the lowest density of interactional markers remains RA 3 (10 interactional markers in 1934 words, i.e., $0.5 \%$ ).

As regards the occurrences of each interactional marker, hedges - the highest occurring interactional markers (i.e., 264 occurrences) - happen the most in RA 12, with 25 occurrences, while they occurred the least in RAs 5 and 20, with 4 occurrences in each. Self-mentions are the second most occurring interactional markers in the data (i.e., 231 occurrences). They are found the most in RA 12 (i.e., 25 occurrences) and the least in RA 11 (i.e., 1 occurrence). Attitude markers are also from the least occurring markers in the data, with 47 occurrences in total. The highest number of occurrences of attitude markers is in RA 2 (i.e., 8 occurrences). Attitude markers are absent, however, in RAs 5 and 19. Boosters are considered one of the least occurring markers in the data, with a total of 28 occurrences. Boosters appear in 10 RAs only, with the most occurrences in RA 11 (i.e., 8 occurrences). Yet, the least occurring markers in the data are the engagement markers. They are used in only 2 RAs (i.e., 1 occurrence in RA 7 and 2 occurrences in RA 18).

\section{Discussion}

The current study investigates the communication strategies that the Egyptian researchers apply in the RAs to communicate their ideas to the readers. These strategies can be observed through analyzing the meta-discourse markers' usage, according to Hyland's (2005) framework. As explained previously, Hyland divides the meta-discourse framework into interactive and interactional markers, each consisting of five types of markers. Overall, the density of meta-discourse markers' usage ranges from 3\% (e.g., RA 3) to 6\% (e.g., RA 6) of the total word count in the analyzed RAs. This low percentage reveals that the authors of the analyzed RAs do not have much employment of textual or interpersonal markers to communicate their knowledge and support their argument.

The analysis of the interactive markers shows interesting results. Interactive markers are the ones which work on organizing the text and ideas and reflect the writer's knowledge in a clear way to the reader. There are five types of interactive markers: transitions, evidentials, code glosses, endophoric markers, and frame markers. Interactive markers as a whole are found to constitute the majority of the meta-discourse markers used. This high prevalence of interactive markers is a feature of hard sciences (including STM disciplines), according to Hyland (2010). However, the huge difference in the occurrence of interactive and interactional markers in the data reveals that the authors of the analyzed RAs 
give high priority to the organization and cohesion of their ideas as well as to the clarity and authenticity of their data, which may result sometimes in excessive use of a certain type of interactive markers in the different RAs analyzed.

Transitions are the most-used meta-discourse marker in the data. Transitions are mainly conjunctions linking independent clauses to mark addition, contrast, or steps in the data ('and, but, yet, therefore, while, because, consequently, besides' are a few examples of the transitions used in the data). The heavy use of transitions is one feature of academic writing, especially on the higher academic levels, where the writers become aware of the need to make the stages of the argument clear to the reader and the ideas presented in a well-linked way (Hyland, 2010). However, transitions are not found to top the occurrence of interactive markers in all 20 RAs. Transitions occur the most, compared to other interactive markers, in RAs 3, 8, 9, 10, 11, 12, 15, 18, and 20. Therefore, despite the high prevalence of transitions in the data as a whole, there are individual differences in their use.

Evidentials are the second type of interactive markers, and they are the second-most occurring meta-discourse marker in the data. The high prevalence of evidentials is another feature of RAs, where the higher the academic level, the more the researchers are keen to provide citations to the information in their RAs to avoid the threat of plagiarism, the more evidentials are used, consequently (Hyland, 2010). Examples of evidentials from the analyzed data are 'according to Dror and Allen, Wu et al [35], [9-13], by Sonis [26].' Evidentials are observed to be the top occurring interactive markers in RAs 1, 2, 4, 5, 6, 7, 14, 16, 17, and 19. As can be seen, transitions and evidentials share the highest frequency counts in $95 \%$ of the RAs analyzed, where transitions are at the top in 9 RAs and evidentials are at the top in 10 RAs. This goes along Hyland's (2010) observations on the use of interactive meta-discourse markers in scientific RAs, which is a point of strength that can be counted in favor of the authors of the analyzed RAs.

Next on the list of the highly occurring interactive markers are the code glosses. Code glosses are terms and statements that are used to clarify information to the reader. Examples of code glosses from the data are 'such as, defined as, e.g., i.e., for instance, (OSA), namely.' The use of code glosses with this high density shows that many of the authors of the analyzed RAs would like to make themselves as understandable as possible. However, things might go further than the norm, such as in RA 13, where code glosses are the highest occurring interactive markers in the RA, representing more than one-third of the total interactive markers and about one-quarter of the total meta-discourse markers, which is a very high percentage. On the very contrary, RA 6 almost 
does not make use of code glosses, where there are only 2 occurrences of code glosses. Therefore, the usage of code glosses varies in the data.

Endophoric markers are interactive markers which are used to refer to information in other parts of the text. The data shows a balanced use of endophoric markers. The ranking of the endophoric markers as the fourth of the interactive markers goes hand-in-hand with the results found by Hyland (2010), where endophoric markers would be used more in hard sciences than social sciences and that they would not be used as heavily as transitions, evidentials, or code glosses, but they would come next in the ranking along with the frame markers. Examples of endophoric markers from the data are as follows: 'the following, Figure 2, as shown in Table 1, (Figure 1).'

The final component of the interactive markers is the frame markers. Frame markers, as the name indicates, are used to label the frames within the argument, whether sequences of discourse goals or topic shifts. These markers are the least occurring interactive markers in the data. Example frame markers from the data include 'initially, in this study, as regards, (1), (2), finally, first, second, as a conclusion.' Not all the analyzed RAs are found to make use of frame markers, however, where RA 9 shows no frame marker occurrences. This low prevalence in frame markers could be considered a weakness since frame markers facilitate clarifying text stages and argument boundaries, which helps the reader better grasp the information presented.

Interactional markers are the other component of the meta-discourse framework. They focus on the personal aspect of the language, addressing the readers, and displaying the author's voice explicitly. There are five types of interactional markers: hedges, self-mentions, attitude markers, boosters, and engagement markers. Interactional markers constitute about one-quarter of the total meta-discourse markers. This low density is in harmony with what is stated in Hyland (2010), where the more the discipline is hard science, the less the interactional markers are used. Hard sciences depend on empirical methods and quantitative interpretation, unlike humanities and social sciences which depend more on personal interpretation and qualitative methods, hence the less prevalence of interactional markers in hard science RAs.

The first type of interactional markers is hedges. According to Hyland (2010), hedges are the most used interactional markers in RAs and they are from the highest occurring meta-discourse markers in academic discourse. In the current study, hedges are found to be the highest occurring interactional marker. Examples of hedges from the data are as follows: 'may, possible, about, approximately, to the best of our knowledge, nearly.' Although hedges rank first in the interactional markers' frequency count, which agrees with Hyland's (2010) 
outcomes, they rank fourth in the overall meta-discourse markers' count, which disagrees with Hyland. This disagreement stems from the fact that the authors in the data use dry language, with more scientific facts and assertive tone. This shows that the authors of the analyzed RAs give more importance to reporting their knowledge and findings than to building relationships with the readers.

The second-most occurring interactional marker in the data is found to be the self-mentions. Examples of self-mentions from the data are 'we, our, us, the authors.' The occurrence of self-mentions in the data is observed to be close the occurrence of hedges, which disaccords with Hyland (2010). Although according to Hyland, the researchers of higher academic levels tend to use more self-mentions to make their contributions to the body of research more acknowledged, self-mentions do not usually have high occurrence in hard science disciplines, unlike the soft disciplines which are more personal. The authors of the analyzed RAs, however, are found to present their voice comfortably, where all RAs analyzed show at least an occurrence of a selfmention.

The remaining three meta-discourse markers are, in descending order of occurrence, attitude markers, boosters, and engagement markers. These three interactional markers are found to be the ones of the least occurrence in the analyzed RAs. Some examples of attitude markers from the data are 'important, unexpectedly, unfortunately, interestingly, as expected.' Although attitude markers occur in 18 RAs, being absent from RAs 5 and 19, they do not have high presence in the data. The authors of the analyzed RAs are not found to be very keen on expressing their attitude towards the facts they portray in their studies. This goes along the impersonal nature of writing in the hard sciences. Boosters have few appearances in the data as well. 'It was clear that, indeed, definitely, certainly, in fact' are some examples of boosters from the data. Again, the authors of the analyzed RAs are observed to be not very keen on using emphasis to boost the force of their ideas. They find that there is not much need for adding emphasizing markers to strengthen the effect of the pure scientific facts they illustrate. Engagement markers are the last type of interactional markers. They rarely occur in the analyzed data. They occur in only in RAs 7 and 18, with 1 occurrence in the former (e.g., the inclusive 'we') and 2 occurrences in the latter (e.g., the inclusive 'we, our'). As mentioned previously, the authors of the analyzed RAs are found to focus more on transmitting the knowledge and findings than on building relationships with the readers and engaging them directly with their argument. 


\section{Conclusion}

The analysis of communication through meta-discourse usage on the unedited first drafts of 20 STM RAs written by Egyptian researchers revealed a number of significant findings. The communication strategies in the text were analyzed using Hyland's (2005) meta-discourse framework. The analysis showed that the greatest share of the markers used was the interactive part, the highest markers of which were transitions and evidentials, reflecting the authors' high interest in textual relations and coordination as well as in documenting the sources of information to avoid plagiarism. The highest occurring interactional marker, on the other hand, was the hedges, which conforms to the expected language of an academic article. Using hedges, the authors could lower the degree of assertion in some parts to leave room for negotiation of the truth of the mentioned information and theories.

All in all, the results of this study seek to make the researchers aware of the problems faced in writing research in English and, hence, lead to increasing the volume of international research publications by Egyptian researchers. The results of this study can help provide the basis for designing specialized English language programs for Egyptian and Arab researchers, as well as graduate students, and enhance their proficiency in writing research in English, enabling them to publish internationally and to increase quality research productivity.

\section{Limitations of the Study}

The qualitative dimension of the current study requires a high degree of interpretation. Despite the validity checks employed to face this threat, such as providing a thick description and adding a quantitative dimension to the analysis, the interpretation of the data may still remain a challenge. In addition, the study adopts an analysis of a relatively small sample. This is because conducting such meta-discourse analysis of all sections of the RA on a larger sample was unfeasible.

\section{Recommendations for Future Research}

More studies can tackle different perspectives such as different nationalities, different academic levels, or different languages. Also, studies can be conducted investigating a single meta-discourse marker or a group of markers to a larger sample. 


\section{References}

Academy of Scientific Research and Technology. Egyptian science and technology indicators. Egyptian Science, Technology and Innovation Observatory, 2016. http://www.asrt.sci.eg/index.php/indicators-survey.

Alotaibi, H. (2016). Comparison of meta-discourse markers in Arabic and English research articles in the introduction and conclusion sections. Linguistics Journal, 10 (1), 182-202.

Bakhtin, M. (1986). The problem of speech genres. In Speech genres and other late essays, B. Mikhail, C. Emerson, \& M. Holquist (Eds), (pp. 60-102). University of Texas Press.

Bazerman, C. (1988). Shaping written knowledge. The University of Wisconsin Press. Wisconsin.

Bhatia, V. (2012). Critical reflections on genre analysis. Iberica, 24 (24), 17-28.

Bhatia, V. (2013). Analysing genre: Language use in professional settings. Routledge, New York.

Bhatia, V. (2014). Worlds of written discourse: A genre-based view. Bloomsbury, London.

Eggins, S. (1997). Genres and Registers of Discourse." In Discourse as Structure and Process, V. Dijk, \& T. Adrianus (Eds.), (pp. 230-256). London.

Fairclough, N. (2004). Analysing discourse: Textual analysis for social research. Routledge, New York.

Merriam-Webster online dictionary. "Genre." Accessed January 2019. https://www.merriam-webster.com/dictionary/genre.

Guziurová, T. (2017). The role of meta-discourse in genre gnalysis: Engagement markers in undergraduate textbooks and research articles." In Contrastive Analysis of Discourse-Pragmatic Aspects of Linguistic Genres, A. Karin, \& D. Lewis (Eds.), (pp. 211-233). Springer International Publishing.

Hosni, H. (2015). Meta-discourse in the discussion section of English and Arabic Linguistics research articles: A cross-Linguistic study." PhD diss., Fayoum University, Egypt.

Hyland, K. (2005). Meta-discourse: Exploring interaction in writing. Continuum, London.

Hyland, K. (2011). Meta-discourse: Mapping interactions in academic writing. Nordic Journal of English Studies, 9(2), 125-143.

Hyland, K. (2011). Academic Discourse." In Continuum Companion to Discourse Analysis, H, Ken, \& B. Paltridge (Eds) (pp. 171-184). Continuum, London. 
Liu, P., \& Xu, H. (2017). A Study of interactional Meta-discourse in English abstracts of Chinese economics research articles." Higher Education Studies, 7 (3). 25-41.

Mina, K., \& Reza, B. (2017). Exploring interactive and interactional metadiscourse markers in discussion sections of social and medical science articles. International Journal of Research in English Education, 2 (4), 1129.

Mozayan, M., Hamid, A., \& Ali, F. (2018). Meta-discourse features in medical research articles: Sub-disciplinary and paradigmatic influences in English and Persian practice. Journal of Research in Applied Linguistics, 9 (1), 83-104.

$\mathrm{Mu}, \mathrm{C}$., Lawrence, J., John, E., \& Huaqing, H. (2015). The use of meta-discourse for knowledge construction in Chinese and English research articles." Journal of English for Academic Purposes, 20 (2015), 135-148.

Paltridge, B. (1997). Genre, Frames, and Writing in Research Settings. John Benjamins Publishing Co, Philadelphia.

Scopus, (2016). "Scimago Journal and Country Rank: Egypt." Accessed June 2017. http://www.scimagojr.com/countrysearch.php?country=eg.

Sorahi, M., \& Mansour, S. (2016). "Meta-discourse in Persian and English research article introductions." Theory and Practice in Language Studies, 6(6), 1175-1182.

Swales, J. (1990). Genre analysis: English in academic and research Settings. Cambridge University Press, Cambridge.

Trosborg, A. (1997). Text typology: Register, genre and text type. In Text typology and translation, T. Anna (Ed.), (pp. 3-23). John Benjamins Publishing Company, Philadelphia. 